\title{
Person-Centered Care Coordination Next Steps in a Long Journey
}

\author{
Jacob HOFDIJK $^{\mathrm{a}, 1}$ and Felix CILLESSEN ${ }^{\mathrm{b}}$ \\ ${ }^{a}$ Casemix-CQT Zorg en Gezondheid, Utrecht, The Netherlands \\ ${ }^{b}$ Hospital Rivierenland Tiel, the Netherlands
}

\begin{abstract}
Citizens of the Netherlands receive excellent care, when they need it, insurance based funded according to the solidarity principle. Maintaining this system is a huge challenge, as we live longer and the demand for care is growing. With an increasing percentage of multi-morbidity in all age groups the need for integrated network organized care is growing at equal pace. Gradually the need to shift focus to prevention is increasingly understood, but a challenging business model is still lacking. The involvement of citizens in maintaining their health requires a focus on managing the social determinants of health. The concept of the holistic problem list and the overarching care plan provides a unique way to combine both health and disease management. Our vision is to bring control to the patient and promote coordination of all active problems across the health and social care network.
\end{abstract}

Keywords. Care continuity, integrated health care systems, health maintenance, problem oriented medical record, interoperability

\section{Introduction}

In recent years the global strategy on people-centered and integrated health services from the World Health Organization has grown support. Research shows that clinical care only contributes $20 \%$ to health, while social and economic factors $40 \%$, health behaviors $30 \%$ and $10 \%$ for physical environment[1]. A focus on these determinants of health will preserve and improve the health of persons, their autonomy and their quality of life. So, we need to integrate health promotion, prevention, disease management and social support in maintaining health from cradle to grave. A growing number of patients have multiple chronic health issues and are treated by a wide range of care providers, often lacking coordination. A holistic person-centered problem list and a well balance careplan actively managed with health and social care providers will guide and coach citizens on their path to continuous health and well-being [2,3]. The overarching careplan will help to combine joint decision-making on health and social care issues, which requires technical, semantical and social interoperable systems.

\footnotetext{
${ }^{1}$ Corresponding Author, Jacob Hofdijk, Casemix-CQT Zorg en Gezondheid, Utrecht, The Netherlands; Email: jacob.hofdijk@casemix.nl
} 


\section{Methods}

For this transition we have adopted the Continuity of Care model of Wagner and applied the INtegrated CAre (INCA) health issue spiderweb to visualize all relevant problems and discuss their progress[4,5]. The concept has been tested in a number of international workshops, resulting in support for the vision and the acceptance of the Blue Line principles[3]. The adoption and implementation of this patient centered approach although requires a major shift in the organization, information flows, funding and governance of all stakeholders, including the citizen / patient.

\section{Results}

The holistic problem list will provide the base for an overarching view to support decision making and care coordination for health, disease and social care issues. The overarching care plan requires a regional data infrastructure to connect both health and social care providers and the record of the patient. Based on the Subjective and Objective data, the patient and provider can jointly record the Assessment and update the Plan (SOAP)[2].

\section{Discussion}

The proposed patient centered approach requires a new digital based clinical network model supported by a regional governant IT infrastructure. The implementation requires endorsement of the new paradigm, the willpower to reorganize health and social systems. Thanks to digital tools to actively measure, patients and providers together will evaluate and manage their health and disease issues. Innovative funding should incentify this endeavor and ease the path to implementation.

\section{Conclusion}

Fueled by the increased use of digital health tools by citizens this approach will stimulate the paradigm shift from illness and care to health and behavior. The journey continues, the patient is aboard, and stakeholders in many countries have learned that collaboration is key for success. So we are on track for next steps to reach better health.

\section{References}

[1] Remington PL, Catlin BB, Gennuso KP. The County Health Rankings: rationale and methods Popul Health Metr. 2015;13:11.

[2] Bleich HL. Lawrence L.Weed and the problem-oriented medical record, MD Computing.1993;10:69-72.

[3] Cillessen FH, Hofdijk WJ. Transition Requirements from Problem List to an Overarching Care Plan for the Support of Person-Centered Care. Stud Health Technol Inform. 2020;272:292-5.

[4] Bodenheimer T, Wagner EH, Grumbach K. Improving primary care for patients with chronic illness. JAMA. 2002;288:1775-9.

[5] van der Heide I, Snoeijs S, Melchiorre MG, Quattribi S, Boerma W, Schellevis V, et al. Innovating care for people with multiple chronic conditions in Europe: an overview, ICARE4EU.NIVEL, Utrecht, 2015. 